\title{
O Traumatismo Cranioencefálico na Vida do Brasileiro
}

\author{
Marcia Maiumi Fukujima \\ Neurologista do Pronto Socorro de Neurologia do Hospital São Paulo - Unifesp, \\ Diretora de Divisão de Atenção ao Paciente do Hospital Estadual de Diadema, Diadema-SP, Brasil.
}

Pacientes que sofreram traumatismo crânio-encefálico (TCE) têm risco duzentas vezes maior que a população geral de desenvolver epilepsia, o que coloca o TCE como uma das principais causas de epilepsia secundária, ao lado de infecçóes, abuso de drogas e história familiar de epilepsia ${ }^{1}$. Além da epilepsia, TCE é também uma das principais causas de incapacidade motora e cognitiva.

Lesóes do parênquima cerebral decorrentes do TCE levam à morte neuronal e proliferação de células da glia, evoluindo com formação de circuitos excitatórios anômalos que resultam em focos epilépticos. O conhecimento desses mecanismos tem contribuído para predizer o desenvolvimento de epilepsia e o seu tempo de latência.

Além da alta mortalidade e do impacto na qualidade de vida do sujeito vítima de TCE que desenvolve epilepsia ${ }^{2}$, os seus custos vêm sendo estudados. Nos Estados Unidos da América, apesar dos traumas cranianos representarem somente $13 \%$ das lesôes traumáticas, são responsáveis por um terço dos custos dos serviços de saúde 3 .

Em um estudo australiano, epilepsia precoce após TCE juntamente com duração da amnésia pós-traumática, escala de coma de Glasgow e anormalidades tomográficas, foi considerada fator preditivo de altos custos referentes ao cuidado prolongado, hospitalização, despesas médicas e de reabilitaçãó ${ }^{4}$.

No Brasil, o gasto médio no Sistema Único de Saúde (SUS) por internação por causa externa, onde os TCE estão incluídos, foi de R $\$ 503,70$ em 2000, chegando a R \$562,24 no Estado de São Paulo. O custo por dia das internaçóes por causa externa chegou a $\mathrm{R} \$ 101,23$ no Brasil e R\$120,23 no Estado de São Paulo. Especificamente para traumatismo craniano o custo por dia foi de $\mathrm{R} \$ 122,83$ no mesmo ano. Apesar de se configurar como quinto maior custo dentre os traumatismos, sendo menor que traumatismo múltiplo, de quadril, de abdômen e membro superior, o impacto dos TCE é grande devido à alta prevalência 5 . Em 2012 o valor total despendido pelo SUS para atendimento de causas externas foi maior que 1 bilhão de reais em 998.994 internações, com valor médio da internação de $\mathrm{R} \$ 1.079,60$, média de permanência de 5,3 dias e taxa de mortalidade de 2,48\% (Datasus). Esses dados sobre custos e valores pagos pelo SUS são exclusivos das internações, não sendo considerados custos ambulatoriais e de clínicas de reabilitação. Somam-se a estes, os custos com medicamentos, materiais necessários aos cuidados domiciliares, cuidador, transporte e aqueles indiretos referentes aos dias não trabalhados pelos pacientes e familiares. Tem-se assim uma ideia do impacto econômico do TCE na vida de um brasileiro.

O estudo conduzido por Di Luca e Lacerda ${ }^{6}$, publicado neste volume da Revista Neurociências, traz nova contribuição relevante ao tema epilepsia após TCE analisando fatores relacionados ao intervalo de tempo entre o trauma e o surgimento da epilepsia. Como apontado pelos próprios autores, há poucos estudos nacionais sobre epilepsia após TCE, o que torna este artigo ainda mais valioso.

$\mathrm{Na}$ amostra estudada, a principal causa de TCE foi acidente de trânsito, seguido de acidente doméstico e queda. Os autores encontraram uma tendência de desenvolvimento mais precoce de epilepsia pós TCE em pacientes com mais que 24 anos e do sexo masculino. A maioria dos casos apresentou epilepsia durante o primeiro ano após TCE, independentemente da gravidade do trauma.

Os fatores relacionados ao surgimento de epilepsia servem de alertas para a condução clínica na prática médica. Esses dados epidemiológicos associados a estudos fisiopatológicos também são úteis para desenvolvimento de pesquisas na área de estratégias preventivas e novas 
drogas para profilaxia, além do tratamento sintomático.

Do ponto de vista de saúde pública, a melhor compreensão dos TCE e suas complicaçóes pode servir para formulação de políticas nacionais focadas na redução internaçóes por causas externas, o que implica especialmente em redução de acidentes e violência de modo geral.

Distribuiçóes de recursos de saúde também podem ser planejadas a partir de dados objetivos sobre evolução dos TCE durante a internação e após a alta hospitalar.

\section{REFERÊNCIAS}

1.Temkin NR. Antiepileptogenesis and seizure prevention trials with antiepileptic drugs: meta-analysis of controlled trials. Epilepsia 2001;42(4):515-524. http://dx.doi.org/10.1046/j.1528-1157.2001.28900.x

2.Kolakowsky-Hayner SA, Wright J, Englander J, Duong T, Ladley-O’Brien $S$. Impact of late post-traumatic seizures on physical health and functioning for individuals with brain injury within the community. Brain Injury 2013;27:578-586.

http://dx.doi.org/10.3109/02699052.2013.765595

3.Max WP, MacKenzie EJP, Rice DPS.Head injuries: Costs and consequences. J Head Trauma Rehabil 1991;6:76-91.

http://dx.doi.org/10.1097/00001199-199106000-00010

4.Ponsford J, Spitz G, Cromarty F, Gifford D, Attwood D. Costs of care following traumatic brain injury. J Neurotrauma 2013; [Epub ahead of print] http://dx.doi.org/10.1089/neu.2012.2843

5.Jorge MHPM, Koizumi MS. Gastos governamentais por causas externas. Rev Bras Epidemiol 2004;7:228-238.

6. Di Luca DG, Lacerda GCB. Time Interval Between Traumatic Brain Injury And Post Traumatic Epilepsy. Rev Neurocienc 2013;21(2):222-228.

http://dx.doi.org/10.4181/RNC.2013.21.855.7p 